\title{
Toll-like receptor 4 in inflammation and angiogenesis: a double-edged sword
}

\author{
Sheeba Murad * \\ Islamabad, Pakistan \\ *Correspondence: sheebamall@yahoo.com; s.mall@asab.nust.edu.pk \\ Edited by: \\ Anton G. Kutikhin, Russian Academy of Medical Sciences, Russia \\ Reviewed by: \\ Fulvio D'Acquisto, Queen Mary University of London, UK \\ Anton G. Kutikhin, Russian Academy of Medical Sciences, Russia
}

Molecular Immunology Lab, Health Care Biotech Department, Atta-Ur-Rahman School of Applied Biosciences, National University of Sciences and Technology,

Keywords: LPS, TLR4, PAMPS, DAMPs, angiogenesis

Toll-like receptors (TLRs) primarily known for the pathogen recognition and subsequent immune responses are being investigated for their pathogenic role in various chronic diseases. The recent reports correlating the microbial infections with chronic disorders such as atherosclerosis have lead to questions in relation to the role of microbial sensors such as TLR4 in an intriguing phenomenon of the inflammation-induced angiogenesis. This article focuses on the possible mechanisms involved in it.

Toll-like receptors comprise a large family of the pathogen-pattern recognition receptors (PPRR) originally identified in Drosophila in the mid 1990s as a Toll protein (1). In Drosophila, it was found to be involved in the resistance against fungal infections (2). The first human homolog for the Toll protein was described in 1997 (3). Since then, 13 mammalian homologs of the TLR family have been identified; including 12 in mice (TLR1-9 and TLR11-13) and 10 in humans (TLR110). TLR 10 is a pseudogene in mice, but is functional in humans (4). The membrane expressed TLRs recognize the pathogenassociated molecular patterns (PAMPs) either directly on the plasma membrane or within the endosomal compartment after the phagocytosis. In addition to the foreign molecules, a range of various endogenous ligands are also detected by TLRs, which suggests a role beyond that of simple pathogen recognition. Endogenous ligands released from the damaged, apoptotic, or fibrotic cells during inflammation, are termed danger-associated molecular patterns (DAMPs). A significant number of DAMPs have been reported for TLR4 $(5,6)$.
TLR4 is one of the best characterized and the first member of the TLR family to be discovered as a PPRR. TLR4 signaling is implicated in the innate immune responses against a wide-range of microbes, including Gram-negative and -positive bacteria, mycobacteria, spirochetes, yeasts, and some viruses such as respiratory syncytial viruses (RSV) and mammary tumor viruses (4). TLR4 is a type I transmembrane protein characterized by an extracellular domain containing leucine-rich repeats (LRRs) and a cytoplasmic tail harboring a conserved region known as Toll/IL-1 receptor (TIR) domain. TLR4, along with its two coreceptors, the myeloid differentiation antigen (MD2) and the LRR protein CD14, forms a trimeric receptor that is involved in the recognition of lipopolysaccharide (LPS). The TLR4 ligand binding causes the $\mathrm{C}$ termini of the ectodomains to move close to each other, thus triggering signaling and inflammation. The diverse interactions between TLRs with their ligands converge into either the MyD88-dependent or MyD88-independent pathways, resulting in the: (1) activation of lymphocytes, (2) up-regulation/expression of costimulatory signals, and (3) release of proinflammatory cytokines/chemokines (7). As sentinels in the innate immunity, TLR expression was thought to be confined to the immune cells such as macrophages, monocytes, and dendritic cells. However, an increasing number of reports show a more diverse expression of TLRs; including epithelial cells, endothelial cells (8), neural and glial cells, thereby playing an important role in tissue-specific inflammation (9).
TLR4 is implicated in a diverse range of pathological processes associated with or induced by angiogenesis including autoimmune diseases such as psoriasis, diabetic retinopathy, thrombosis, and inflammatory disorders including arthritis and atherosclerosis and cancer $(10,11)$. It has been proposed that TLR4 contributes to these diseases through inflammationinduced angiogenesis. The recent association between bacterial infections and atherosclerosis has intensified the search for the biological functions of TLRs especially TLR4 in blood vessel formation (12). The exact mechanism needs to be elucidated.

Angiogenesis is the normal process required for the development of an extensive vasculature. With its over 60 trillion endothelial cells, the vascular network is the first and the largest organ to develop in the human body (13). It mainly occurs during embryonic development. In adults, angiogenesis is a highly regulated process only occurring during the retinal development, in the adult intestinal villi and in the female reproductive organs (14). The postnatal angiogenesis may take place through one of the two possible mechanisms; (1) vasculogenesis - the de novo generation of blood vessels from endothelial progenitor cells (EPCs) or mesoderm and more commonly (2) angiogenesis, which is the sprouting/branching of the pre-existing blood vessels - together they are called neoangiogenesis. Angiogenesis is a highly complex series of sequential events orchestrating various molecular events involving multiple cell populations, cytokines, and chemokines. It takes place in two important steps; (1) formation of a nascent 
vascular network and (2) its subsequent maturation. The degradation of extracellular matrix (ECM) allows the sprouting of EPCs from old vessel into an avascular space and differentiation into nascent vasculature under the influence of proangiogenic factors. The maturation process involves the recruitment of supporting cells (mural cells) and vessel remodeling. Mural cells include vascular smoothmuscle cells (VSMC) in arteries, arterioles, and veins; pericytes in capillaries (15, 16). They provide structural integrity to the developing vasculature and may also interact with the endothelial cells, through paracrine signaling. Pro-angiogenic factors such as the vascular endothelial growth factor (VEGF); the basic fibroblast growth factor (bFGF); the transforming growth factor beta (TGF- $\beta$ ); the platelet-derived growth factor (PDGF); the tumor necrosis factor alpha (TNF- $\alpha)$; the insulin-like growth factor-1 (IGF-1); the monocyte chemotactic protein (MCP)-1; interleukin (IL) -6 and 8 all help in the recruitment of cells, ECM degradation, and with vessel development and maturity (14). An important empirical role played by TLR4 in the lymphocytic activation, recruitment, and release of cytokines is evident in TLR4deficient mice. Such mice are reported to display significantly impaired expression of pro-inflammatory cytokines after reperfusion triggered by retinal ischemia injury (17). The process of lymphangiogenesis was shown to be affected in TLR4-deficient mice through lack of macrophage recruitment by TLR4 ${ }^{+}$lymphatic endothelial cells (LEC) (7).

As one of the two main sources of cytokines, macrophages play a critical role in the leukocyte trafficking and the postnatal angiogenesis. TLR4-mediated LPSactivated macrophages have been shown to be an important source of proangiogenic factors. Accumulating evidence shows that antigenic stimulation and the surrounding cytokine environment can have profound effects on the activation status and the functional capabilities of macrophages. Although there are various schools of thought regarding the macrophage activation status, here, we focus on two; the M1 and M2 phenotypes. The classical activation or M1 phenotype of macrophages contributes substantially toward anti-microbial immune responses via the production of proinflammatory cytokines such as IL-6, IL-8, IL-12, inducible nitric oxide synthase (iNOS), and interferons (IFNs) (18) (Figure 1). The alternate activation of macrophages may lead to the M2 phenotype, which is reported to be involved in the wound repair and fibrosis by contributing toward angiogenesis through the VEGF production (19). The strong mitogenic effect on the endothelial cells and the induction of vascular permeability are the pro-angiogenic effects, which makes VEGF the most potent simulator of angiogenesis. In murine macrophages and other TLR$^{+}$cell populations, a strong synergism is reported to significantly influence the production of VEGF. Endotoxins (including LPS) together with the growth factors and cytokines such as IFN$\gamma$, TGF- $\beta$, IL- 1 , and IL- 6 have been implicated in a significant augmentation in VEGF levels (20-24). In this regard, the synergism reported between TLR4 and adenosine receptor $2 \mathrm{~A}\left(\mathrm{~A}_{2 \mathrm{~A}} \mathrm{R}\right)$ in the murine macrophages (M2) is noteworthy (Figure 1) (25). Adenosine receptor signaling plays an important role in inflammation. Adenosine is produced by many different cell types and is elevated in conditions such as hypoxia, ischemic conditions, and stress. So far, four adenosine receptors have been reported, i.e., the $A_{1}, A_{2 A}, A_{3 B}$, and $A_{3}$ receptors (26). The synergistic effect of $A_{2 A} R$ is not restricted to TLR4, but TLR2, 7, and 9 also lead to high VEGF production in the presence of adenosine signaling (22). Both TLR4 and $\mathrm{A}_{2 \mathrm{~A}} \mathrm{R}$ were shown to signal through hypoxia inducible factor (HIF) $-1 \alpha$ and hypoxia response element (HRE) (27). Although the TLR4 along with its co-receptors are known to be expressed on the endothelial cells, it is not yet known whether the endothelial cells share the synergistic effect of TLR4 with $\mathrm{A}_{2 \mathrm{~A}} \mathrm{R}$. The transcriptional expression of $A_{2 A} R$ has been reported on the endothelial cells; however, there are limited number of studies in this context. Many groups have demonstrated potent endothelial responses to LPS in vitro (28-32). However, there are reports supporting the in vivo role of LPS in postnatal angiogenesis. A study conducted in murine tumor model (metastatic) demonstrated the proangiogenic effects of LPS. The LPS-induced growth and metastasis of $4 \mathrm{~T} 1$ experimental lung metastases model was shown to take place through increased angiogenesis, vascular permeability, and tumor cell migration (33). The LPS-mediated angiogenic effects can be reversed through TLR4 downregulation. While studying the anti-inflammatory affects of a compound known as Baicalein, its anti-angiogenic effects were shown to be carried out through the downregulation of TLR4 and its downstream mitogen-activated phosphate kinase (MAPK) pathway (34).

The ubiquitous and abundantly expressed DAMPs are often found in association with different anomalies. One such commonly expressed protein is high mobility group chromatin protein B1 (HMGB-1). It is a nuclear DNA binding protein released by injured or necrotic cells. Resting, non-activated inflammatory cells, such as monocytes or macrophages, contain HMGB-1 in their nuclei. When these cells are activated by LPS or inflammatory cytokines, HMGB-1 translocates in the cytoplasm, undergoes acetylation, and is exocytosed. It is evident that excreted HMGB-1 acts like a pro-inflammatory cytokine, therefore, HMGB-1 can be regarded as a signal of tissue injury and a mediator of inflammation (35). Macrophage-derived HMGB-1 has been shown to increase the endothelial cell proliferation, sprouting, and chemotaxis by stimulating the migration of adherent cells, such as fibroblasts and smooth-muscle cells. In a recent study, HMGB-1-TLR4 signaling was reported to be an important mediator in retinal neoangiogenesis in an oxygen-induced retinopathy murine model (36). HMGB-1 is an important marker for tumor endothelial cells and was shown to be necessary for the sustained expression of pro-angiogenic genes. A positive feedback mechanism has been suggested for the HMGB-1 expression and that of its cognate receptors, i.e., TLR4 and receptor for advanced glycation end products (RAGE) on the endothelial cells. Thus HMGB-1 may prove to be a promising target for interfering with cancer-related angiogenesis (37). However, there is some disagreement in relation to the HMGB-1 as an endogenous ligand for TLR4. The lack of an LPS-free in vitro system makes it difficult to study the signaling resulting exclusively 


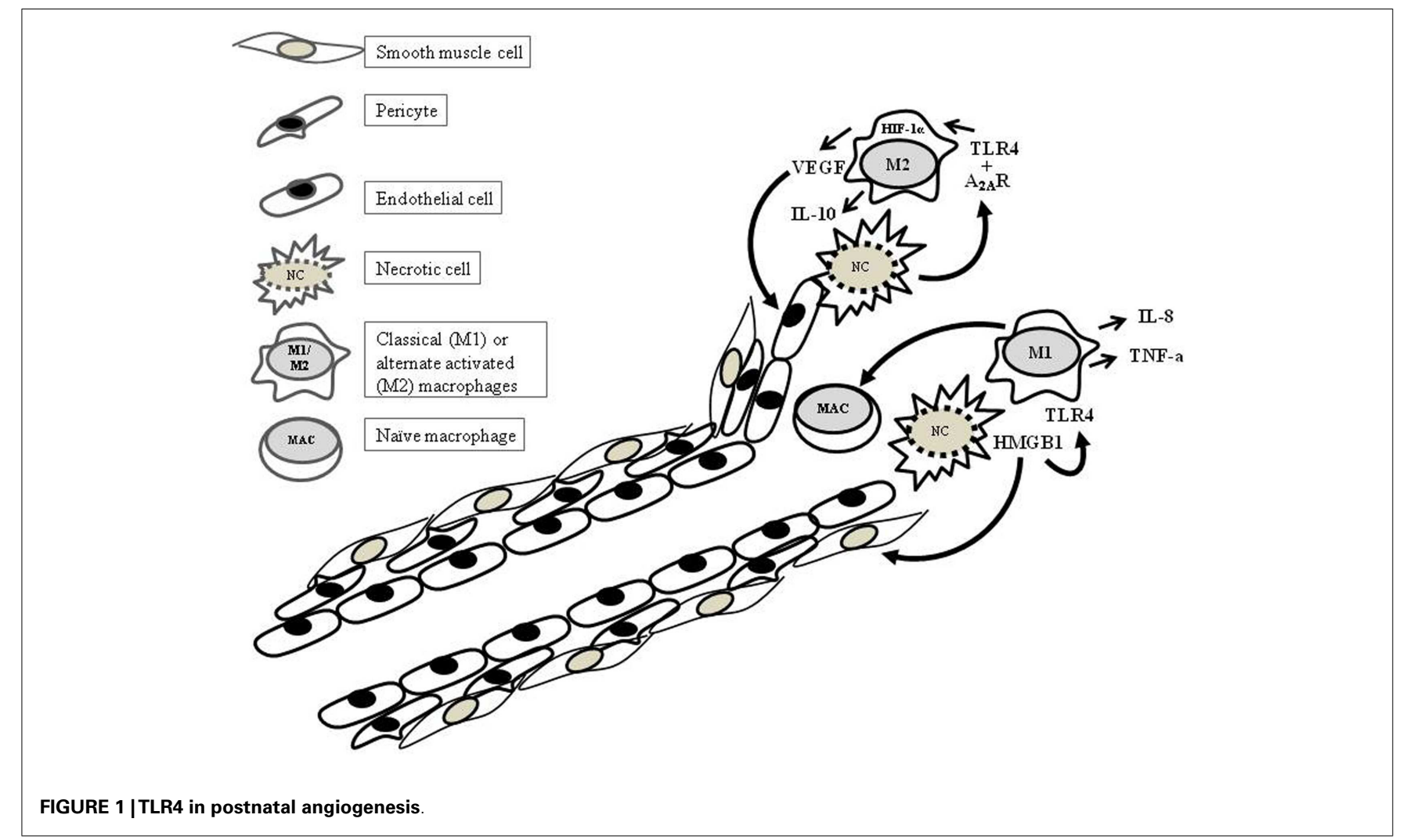

from the TLR4-ligands other than LPS. Even small traces of LPS can upregulate TLR4 and can affect the interpretation of results.

Ischemic diseases are one of the major causes of morbidity and mortality. Treatment of such disorders requires angiogenesis. It is therefore the prime goal of therapeutic angiogenesis to achieve this. However, the close association between angiogenesis and inflammation presents an obstacle to the success of the therapy. Most of the pro-angiogenic factors are also pro-inflammatory. Therefore, the reperfusion of ischemic tissues often results in injury due to the microvascular dysregularities and inflammation (edema) associated with it. The activated endothelial cells lead to an imbalance between oxygen radicals and nitric oxide causing the release of inflammatory mediators $(38,39)$. The TLR4-deficient mice have been a valuable tool for studying the role of TLR4 in tissue-related ischemia-reperfusions in vivo. A recent study reported the role of TLR4-mediated responses contributing to the oxygen-induced neovascularization in ischemic neural tissue (retina).
The TLR4-dependent responses, proposed to be mediated through HMGB-1 release in the ischemic neural tissue were found to be impaired in TLR4-deficient mice, revealing an important angiogenic role of TLR4 in neural tissues (36). On the other hand, there are several studies highlighting the inflammatory role of TLR4 in various reperfusion-ischemic models in tissues such as liver, lung, and intestine. Most of these studies showed reduced inflammation in relation to the injury induced by the reperfusion of various organs after a period of ischemia in TLR4-deficient mice, thus, highlighting the inflammatory role of TLR4 in reperfusion-related injury models, without significant compromise in angiogenesis (40-43). Considering these reports, the dual role of TLR4 in angiogenesis and inflammation comes to light, which seems to be governed by an intricate balance between the inhibitory or stimulatory factors that may be tissue-specific. Nevertheless, TLR4 remains a promising target for suppressing the undesired and prolonged inflammatory responses. In this regard, various synthetic and plantderived therapies are currently being tested.
TLR4-blocking through small molecule inhibitors and antibodies are being evaluated in pre-clinical trials for their efficacy in various inflammatory conditions. Novimmune is a humanized counterpart of rat anti-TLR4 monoclonal antibody; $1 \mathrm{~A} 6$, found to reduce inflammation in a murine colitis model. It is undergoing preclinical evaluation for the treatment of the inflammatory bowel diseases (44-46). Various plant-derived drugs such as wogonoside and celastrol have shown promising results against TLR4-mediated LPSinduced angiogenesis in pre-clinical drug testing $(47,48)$.

In conclusion, it can be said that the close association between inflammation and angiogenesis makes the therapeutic modulation of TLR4 somewhat challenging and can lead to potential side effects. Therefore, the fine tuning of TLR 4 and its associating proteins is required in order to circumvent the undesired inflammatory or angiogenic responses associated with TLR4 targeting in various pathologies. For that purpose, further insight into its in vivo networking and the effects of TLR4 targeting in various pathologies through the use 
of closely related animal disease models is required.

\section{REFERENCES}

1. Taguchi T, Mitcham JL, Dower SK, Sims JE, Testa JR. Chromosomal localization of TIL, a gene encoding a protein related to the Drosophila transmembrane receptor Toll, to human chromosome 4p14. Genomics (1996) 32:486-8. doi:10.1006/ geno.1996.0150

2. Fehlbaum P, Bulet P, Michaut L, Lagueux M, Broeckaert W, Hetru C, et al. Insect immunity: septic injury of Drosophila induces the synthesis of a potent antifungal peptide with sequence homology to plant antifungal peptides. J Biol Chem (1994) 269:33159-33163.

3. Medzhitov R, Preston-Hurlburt P, Janeway C. A human homologue of the Drosophila Toll protein signals activation of adaptive immunity. Nature (1997) 388:394-397. doi:10.1038/41131

4. Pichlmair A, Reis e Sousa C. Innate recognition of viruses. Immunity (2007) 27:370-83. doi:10.1016/ j.immuni.2007.08.012

5. Brikos C, O'Neill LA. Signalling of Toll-like receptors. Handb Exp Pharmacol (2008) 183:21-50. doi:10.1007/978-3-540-72167-3_2

6. Yu L, Wang L, Chen S. Endogenous Toll-like receptor ligands and their biological significance. $J$ Cell Mol (2010) 14:2592-603. doi:10.1111/j.15824934.2010.01127.x

7. Kang S, Lee SP, Kim KE, Kim HZ, Mémet S, Koh GY. Toll-like receptor 4 in lymphatic endothelial cells contributes to LPS-induced lymphangiogenesis by chemotatic recruitment of macrophages. Blood (2009) 113(11):2605-13. doi: 10.1182/blood-2008-07-166934

8. Andonegui G, Bonder CS, Green F, Mullaly SC, Zbytnuik L, Raharjo E, et al. Endothelium-derived Toll-like receptor-4 is the key molecule in LPSinduced neutrophil sequestration into lungs. J Clin Invest (2003) 111:1011-20. doi:10.1172/JCI16510

9. Zhou H, Lapointe BM, Clark SR, Zbytnuik L, Kubes P. A requirement for microglial TLR4 in leukocyte recruitment into brain in response to lipopolysaccharide. J Immunol (2006) 177(11):8103-10. doi: 10.4049/jimmunol.177.11.8103

10. Satoh M, Ishikawa Y, Minami Y, Takahashi Y, Nakamura M. Role of Toll like receptor signaling pathway in ischemic coronary artery disease. Front Biosci (2008) 13:6708-15. doi:10.2741/3183

11. Ehsan N, Murad S, Ashiq T, Mansoor MU, Gul S, Khalid S, et al. Significant correlation of TLR4 expression with the clinicopathological features of invasive ductal carcinoma of the breast. Tumour Biol (2013) 34(2):1053-9. doi:10.1007/s13277013-0645-y

12. Frantz S, Ertl G, Bauersachs J. Mechanisms of disease: Toll-like receptors in cardiovascular disease. Nat Clin Pract Cardiovasc Med (2007) 4:444-54. doi: $10.1038 /$ ncpcardio0938

13. Aird WC. Phenotypic heterogeneity of the endothelium: I. Structure, function, and mechanisms. Circ Res (2007) 100(2):158-73. doi:10.1161/ 01.RES.0000255691.76142.4a

14. Carmeliet P. Angiogenesis in life, disease and medicine. Nature (2005) 438:932-6. doi:10.1038/ nature 04478
15. Sato TN. Vascular development: molecular logic for defining arteries and veins. Curr Opin Hematol (2003) 10:131-5. doi:10.1097/00062752200303000-00006

16. Yancopoulos GD, Davis S, Gale NW, Rudge JS, Wiegand SJ, Holash J. Vascular-specific growth factors and blood vessel formation. Nature (2000) 407:242-8. doi:10.1038/35025215

17. Dvoriantchikova G, Barakat DJ, Hernandez E, Shestopalov VI, Ivanova D. Liposome-delivered ATP effectively protects the retina against ischemia-reperfusion injury. Mol Vis (2010) 16: 2882-90.

18. Pinhal-Enfield G, Ramanathan M, Hasko G, Vogel SN, Salzman AL, Boons GJ, et al. An angiogenic switch in macrophages involving synergy between Toll-like receptors 2, 4, 7, and 9 and adenosine $\mathrm{A}(2 \mathrm{~A})$ receptors. $A m$ Pathol (2003) 163(2):711-21. doi:10.1016/S00029440(10)63698-X

19. Wu WK, Llewellyn OP, Bates DO, Nicholson LB, Dick AD. IL-10 regulation of macrophage VEGF production is dependent on macrophage polarisation and hypoxia. Immunobiology (2010) 215(910):796-803. doi:10.1016/j.imbio.2010.05.025

20. Pertovaara L, Kaipainen A, Mustonen T, Orpana A, Ferrara N, Saksela O, et al. Vascular endothelial growth factor is induced in response to transforming growth factor-beta in fibroblastic and epithelial cells. J Biol Chem (1994) 269:6271-4.

21. Levy AP, Levy NS, Wegner S, Goldberg MA. Transcriptional regulation of the rat vascular endothelial growth factor gene by hypoxia. J Biol Chem (1995) 270:13333-40. doi:10.1074/jbc.270. 22.13333

22. Cohen T, Nahari D, Cerem LW, Neufeld G, Levi BZ. Interleukin 6 induces the expression of vascular endothelial growth factor. J Biol Chem (1996) 271:736-741. doi:10.1074/jbc.271.2.736

23. Gille J, Swerlick RA, Caughman SW. Transforming growth factor-alpha-induced transcriptional activation of the vascular permeability factor (VPF/VEGF) gene requires AP-2-dependent DNA binding and transactivation. EMBO J (1997) 16:750-759. doi:10.1093/emboj/16.4.750

24. Xiong M, Elson G, Legarda D, Leibovich SJ. Production of vascular endothelial growth factor by murine macrophages: regulation by hypoxia, lactate, and the inducible nitric oxide synthase pathway. Am J Pathol (1998) 153:587-98. doi:10.1016/ S0002-9440(10)65601-5

25. Leibovich SJ, Chen JF, Pinhal-Enfield G, Belem PC, Elson G, Rosania A, et al. Synergistic upregulation of vascular endothelial growth factor expression in murine macrophages by adenosine $\mathrm{A}(2 \mathrm{~A})$ receptor agonists and endotoxin. Am J Pathol (2002) 160(6):2231-44. doi:10.1016/ S0002-9440(10)61170-4

26. Fredholm BB, Abbracchio MP, Burnstock G, Daly JW, Harden TK, Jacobson KA, et al. Nomenclature and classification of purinoreceptors. Pharmacol Rev (1994) 46:143-56.

27. Ramanathan M, Pinhal-Enfield G, Hao I, Leibovich SJ. Synergistic up-regulation of vascular endothelial growth factor (VEGF) expression in macrophages by adenosine $\mathrm{A} 2 \mathrm{~A}$ receptor agonists and endotoxin involves transcriptional regulation via the hypoxia response element in the
VEGF promoter. Mol Biol Cell (2007) 18:14-23. doi:10.1091/mbc.E06-07-0596

28. Fan J, Frey RS, Malik AB. TLR4 signaling induces TLR2 expression in endothelial cells via neutrophil NADPH oxidase. J Clin Invest (2003) 112:1234-43. doi:10.1172/JCI200318696

29. Li X, Tupper JC, Bannerman DD, Winn RK, Rhodes CJ, Harlan JM. Phosphoinositide 3 kinase mediates Toll-like receptor 4 -induced activation of NF-kappa B in endothelial cells. Infect Immun (2003) 71(8):4414-20. doi:10.1128/IAI.71.8.44144420.2003

30. Lloyd K, Kubes P. GPI-linked endothelial CD14 contributes to the detection of LPS. Am J Physiol Heart Circ Physiol (2006) 291(1):H473. doi:10. 1152/ajpheart.01234.2005

31. Faure E, Equils O, Sieling PA, Thomas L, Zhang FX, Kirschning CJ, et al. Bacterial lipopolysaccharide activates NF-kappaB through Toll-like receptor 4 (TLR-4) in cultured human dermal endothelial cells. Differential expression of TLR-4 and TLR-2 in endothelial cells. J Biol Chem (2000) 275(15):11058-63. doi:10.1074/jbc.275.15.11058

32. Zhang FX, Kirschning CJ, Mancinelli R, Xu XP, Jin Y, Faure E, et al. Bacterial lipopolysaccharide activates nuclear factor-kappaB through interleukin1 signaling mediators in cultured human dermal endothelial cells and mononuclear phagocytes. J Biol Chem (1999) 274(12):7611-4. doi:10.1074/ jbc.274.12.7611

33. Ling Y, Wang L, Chen Y, Feng F, You Q, Lu N, et al. Baicalein inhibits angiogenesis induced by lipopolysaccharide through TRAF6 mediated Tolllike receptor 4 pathway. Biomed Prev Nutr (2011) 1:172-9. doi:10.1016/j.bionut.2011.06.013

34. Harmey JH, Bucana CD, Lu W, Byrne AM, McDonnell S, Lynch C, et al. Lipopolysaccharide-induced metastatic growth is associated with increased angiogenesis, vascular permeability and tumor cell invasion. Int J Cancer (2002) 101:415-22. doi:10. 1002/ijc. 10632

35. Wu CX, Sun H, Liu Q, Guo H, Gong JP. LPS induces HMGB1 relocation and release by activating the NF-kB-CBP. Signal transduction pathway in the murine macrophage-like cell line RAW264.7. J Surg Res (2012) 175(1):88-100. doi:10.1016/j.jss.2011. 02.026

36. He C, Sun Y, Ren X, Lin Q, Hu X, Huang X, et al. Angiogenesis mediated by Toll-like receptor 4 in ischemic neural tissue. Arterioscler Thromb Vasc Biol (2013) 33(2):330-8. doi:10.1161/ATVBAHA. 112.300679

37. Van Beijnum JR, Nowak-Sliwinska P, van den Boezem E, Hautvast P, Buurman WA, Griffioen AW. Tumor angiogenesis is enforced by autocrine regulation of high-mobility group box 1. Oncogene (2013) 32(3):363-74. doi:10.1038/onc.2012.49

38. Carden DL, Granger DN. Pathophysiology of ischaemia-reperfusion injury. J Pathol (2000) 190(3):255-66. doi:10.1002/(SICI)10969896(200002)190:3<255::AID-PATH526>3.0. $\mathrm{CO} ; 2-6$

39. Hori M, Nishida K. Toll-like receptor signaling defensive or offensive for the heart? Circ Res (2008) 102:137-9. doi:10.1161/CIRCRESAHA. 107.170225

40. Oyama J, Blais C Jr, Liu X, Pu M, Kobzik L, Kelly RA, et al. Reduced myocardial ischemia-reperfusion 
injury in Toll-like receptor 4-deficient mice. Circulation (2004) 109(6):784-9. doi:10.1161/01.CIR. 0000112575.66565 .84

41. Cao CX, Yang QW, Lv FL, Cui J, Fu HB, Wang JZ. Reduced cerebral ischemia-reperfusion injury in Toll-like receptor 4 deficient mice. Biochem Biophys Res Commun (2007) 353(2):509-14. doi:10. 1016/j.bbrc.2006.12.057

42. Tatum PM Jr, Harmon CM, Lorenz RG, Dimmitt RA. Toll-like receptor 4 is protective against neonatal murine ischemia-reperfusion intestinal injury. J Pediatr Surg (2010) 45(6):1246-55. doi:10.1016/ j.jpedsurg.2010.02.093

43. Ellett JD, Evans ZP, Atkinson C, Schmidt MG, Schnellmann RG, Chavin KD. Toll-like receptor 4 is a key mediator of murine steatotic liver warm ischemia/reperfusion injury. Liver Transpl (2009) 15(9):1101-9. doi:10.1002/lt.21782

44. Ungaro R, Fukata M, Hsu D, Hernandez Y, Breglio K, Chen A, et al. A novel Toll-like receptor 4 antagonist antibody ameliorates inflammation but impairs mucosal healing in murine colitis. Am J Physiol Gastrointest Liver Physiol (2009) 296:G1167-79. doi:10.1152/ajpgi.90496.2008

45. Edfeldt K, Swedenborg J, Hansson GK, Yan ZQ Expression of Toll-like receptors in human atherosclerotic lesions: a possible pathway for plaque activation. Circulation (2002) 105(10):1158-61.

46. Simpson JL, Grissell TV, Douwes J, Scott RJ, Boyle MJ, Gibson PG. Innate immune activation in neutrophilic asthma and bronchiectasis. Thorax (2007) 62:211-8. doi:10.1136/thx.2006.061358

47. Chen Y, Lu N, Ling Y, Gao Y, Wang L, Sun Y, et al. Wogonoside inhibits lipopolysaccharide-induced angiogenesis in vitro and in vivo via Toll-like receptor 4 signal transduction. Toxicology (2009) 259(12):10-7. doi:10.1016/j.tox.2009.01.010

48. Ni H, Zhao W, Kong X, Li H, Ouyang J. Celastrol inhibits lipopolysaccharide-induced angiogenesis by suppressing TLR4-triggered nuclear factor-kappa B activation. Acta Haematol (2014) 131(2):102-11. doi:10.1159/000354770
Conflict of Interest Statement: The author declares that the research was conducted in the absence of any commercial or financial relationships that could be construed as a potential conflict of interest.

Received: 21 April 2014; accepted: 22 June 2014; published online: 07 July 2014.

Citation: Murad S (2014) Toll-like receptor 4 in inflammation and angiogenesis: a double-edged sword. Front. Immunol. 5:313. doi: 10.3389/fimmu.2014.00313

This article was submitted to Tumor Immunity, a section of the journal Frontiers in Immunology.

Copyright (c) 2014 Murad. This is an open-access article distributed under the terms of the Creative Commons Attribution License (CC BY). The use, distribution or reproduction in other forums is permitted, provided the original author(s) or licensor are credited and that the original publication in this journal is cited, in accordance with accepted academic practice. No use, distribution or reproduction is permitted which does not comply with these terms. 